\title{
EL MURO ENTERRADO
}

\author{
Roberto Ampuero
}

\begin{abstract}
A veinte años de la caída del Muro de Berlín, sostiene Roberto Ampuero en este ensayo, esa frontera de hormigón sigue rondando como un fantasma ominoso nuestra historia nacional y sus perspectivas. No habrá reencuentro del país, ni justicia, ni perdón, ni ampliación de la tolerancia, ni profundización de la democracia — se señala— si la izquierda chilena que no criticó públicamente el Muro (como no critica hoy públicamente los 50 años del castrismo) persiste en el silencio y la evasión. Centrándose exclusivamente en las víctimas de "nuestra" dictadura, esa izquierda continúa rehuyendo el debate sobre las dictaduras de "los partidos aliados" y sus víctimas, como su responsabilidad por haber alimentado el quiebre de la tradición democrática en Chile.

Escasean hoy en nuestro país - afirma el escritor chilenomesas redondas, libros de ensayo o novelas que aborden este tema desde una perspectiva amplia, que apunten a la reflexión y construcción de nuevas plataformas de acuerdo nacional, y que nos permitan escribir un relato coherente e
\end{abstract}

Roberto Ampuero. Escritor, doctor en filosofía, profesor de la Universidad de Iowa y columnista. Entre sus obras figuran El Caso Neruda, Nuestros Años Verde Olivo, Los Amantes de Estocolmo y la saga del detective privado Cayetano Brulé.

Estudios Públicos, 115 (invierno 2009). 
inclusivo de nuestra historia política reciente. Hay que combatir — agrega — la tendencia a ver sólo lo que queremos ver, pues no hay justicia sin verdad.

Frente a la omisión de la izquierda chilena —advierte Ampuero- - existe por cierto un correlato de centro y derecha, donde también se adeuda la autocrítica por el apoyo brindado a un régimen que violó derechos humanos.

Palabras clave: Muro de Berlín; izquierda política chilena; guerra fría; historia política de Chile; historia política de Alemania; socialismos reales; derechos humanos.

$\mathrm{D}$ urante este verano europeo paseé a diario por lo que queda de la antigua franja de la muerte de Berlín, esa hasta hace 20 años silenciosa tierra de nadie, esa cicatriz amplia y despejada que dividía a la ciudad y en cuyo extremo occidental se alzaba el Muro que durante casi tres decenios los germano-orientales no pudieron cruzar. Siempre al término del paseo - fuese en la mañana tibia o en medio de la brisa de la tarde - regresaba a mi departamento de la Oderbergerstrasse, en el antiguo barrio obrero de Prenzlauer Berg abrigando sentimientos mezclados y convencido de que ese Muro, ya inexistente por fortuna, es, o era, también chileno, que esa larga lápida horizontal, que mantuvo un prolongado diálogo con nosotros, desde el pasado nos exige autocrítica, reflexiones y respuestas.

Porque a primera vista, como chileno, uno pudiera pensar que ese Muro corresponde a otros, a otras historias nacionales y culturas, a otros destinos y derroteros políticos, en fin, a la vieja Europa o las superpotencias, tal vez. Sin embargo, esa valla de hormigón fue, o es, también chilena, simbólicamente hablando, se entiende. Cuando regresaba a mi departamento después del paseo, sentía, por una parte, la alegría por los millones de alemanes del Este, en algún momento conciudadanos míos, que en noviembre de 1989 conquistaron pacíficamente la libertad; y por otra, la irritación por el silencio que aún guardan compatriotas - líderes o militantes de izquierda de entonces- que respaldaron tácita o implícitamente tanto esa frontera cri- 
minal para justificar un régimen supuestamente humanista como la utopía global supuestamente progresista, que los inspiraba. Sí, me irrita esa complicidad abierta o embozada de la que se desentendieron tras el derrumbe del Muro para enfocarse en la recuperación de la democracia en Chile.

Cuando contemplo la antigua franja de la muerte o los escasos restos del Muro pienso también en Chile y nuestra historia y sus perspectivas. Pese a que el tiempo pasa, la frontera, construida y derribada por alemanes, guarda una porfiada relación con la política chilena, con algunos de sus sueños profundos y algunas de sus pesadillas esperpénticas, algo que hoy muchos, que demandan $-\mathrm{y}$ con razón- cultivar la memoria histórica nacional entre 1973 y 1989, cubren con el manto del olvido. Sin embargo, el Muro sigue allí, es nuestro fantasma, como dirían Marx y Engels, un fantasma que aun galopa por Chile, inquietando, ruborizando y enfureciendo a sus antiguos adherentes. Aunque fue alzado muy lejos de nosotros y ya desapareció, también es chileno, porque Chile fue parte de la Guerra Fría y uno de sus campos de batalla. Antes de sucumbir bajo las mandarrias del pueblo alemán, el Muro bien podría haber parodiado a John F. Kennedy diciéndonos: "Ich bin ein Chilener", porque entre nosotros hubo muchos que lo abrazaron y pulieron. Pero desde su polvo nos sigue recordando banderas, programas y una solidaridad que algunos hoy se apresuran a olvidar.

No puedo tolerar la declinación de responsabilidades individuales o de partidos ante esa construcción de concreto, acompañada siempre de alambradas, campos minados, gendarmes con metralletas y perros guardianes, porque fue ella la que posibilitó en última instancia la existencia del socialismo real en Europa, la proyección de una utopía y la concreción de un modelo que se tornó argumento, inspiración y aliado de un sector gravitante en nuestra sociedad. Hablo de un sector político que en 1989, cuando coincidió prácticamente el derrumbe de los socialismos reales con la derrota de Pinochet, corrió a sepultar su complicidad con el Muro pese a que su programa socialista para Chile se inspiraba en modelos que sólo florecían al amparo de ese muro y que condujeron, en tanto utopía, a nuestra peor tragedia en el siglo XX.

Quiero ser claro: Al proclamar la existencia de una dimensión chilena del Muro de Berlín, no me mueve un ajuste de cuentas con 
nadie sino el afán de proyectar, como testigo privilegiado de esa etapa de nuestra historia, luz sobre episodios apenas alumbrados de ella. Sólo la verdad posibilita al final la justicia, la escritura de una historia inclusiva, sin silencios y pluralista, el reencuentro del país, el perdón, la ampliación de la tolerancia, la profundización de la democracia. Para que no se me tilde de parcial: frente a ese silencio de la izquierda chilena con respecto al fracaso de su horizonte utópico del siglo XX, silencio que le permite eludir la autocrítica, la reflexión histórica y su responsabilidad, existe un correlato de centro y derecha, donde también se adeuda la autocrítica por el apoyo que esos sectores brindaron a un régimen que, si bien trajo cambios macro-económicos esenciales al país, sin los cuales Chile no ocuparía el sitial de hoy en el contexto latinoamericano, violó derechos humanos. Es precisamente esa colusión del silencio entre izquierda, centro y derecha, lo que nos impide escribir una historia reciente de carácter "nacional".

Deberíamos combatir drásticamente la tendencia de ver sólo lo que queremos ver. Un artículo que examina la caída del Muro de Berlín despierta interés en un derechista e incomodidad en un izquierdista, y lo opuesto ocurre con uno que aborde la dictadura militar. De ese modo no surgen debates sino exposiciones políticas paralelas, diálogos de sordo. No se superan diferencias, los odios siguen palpitando e incubándose de nuevo, legándose como si la capacidad de aprendizaje se hubiese atrofiado. No es casual que tendamos a celebrar la consecuencia en política, como si la consecuencia fuese garantía y expresión suprema de honestidad y entrega personal, pero olvidemos que ella en sí significa poco o cualquier cosa, como lo demuestra la consecuencia indiscutible de Fidel Castro o Francisco Franco, de Erich Honecker o Alfredo Stroessner, de José Stalin o Adolfo Hitler por permanecer en el poder y atar el destino de sus respectivos pueblos a su destino personal. ¿Alguien más consecuente hasta la muerte que los políticos que he nombrado? Somos incapaces, por otro lado, de generar respeto por el derecho a equivocarse y por la grandeza que implica rectificar. Nos hace falta legitimar en política la virtud del converso, la valentía de quien cambia de opinión porque los hechos han cambiado, el coraje de aquel que no se subordina a la filosofía tribal de mantener de la cuna a la tumba las mismas convicciones. En el fondo, lo que subyace ahí es una suerte de intolerancia, una pérdida de flexibilidad, una obstinación del pensamiento. $\mathrm{Y}$ en ese sentido nos hace falta desprendernos como 
individuos de la lógica de los partidos políticos y aplaudir al swing voter, al ciudadano que en cada elección vota de acuerdo a su conciencia y escrutinio, premiando al mejor candidato, castigando a quien incumple, siendo libre, no garantizando votos a nadie per sécula, dejando en la zozobra al político que cumple a medias las tareas, subrayando la propia independencia, emitiendo el voto como veredicto.

\section{El Muro de Berlín es también chileno}

Insisto: el Muro de Berlín fue, o es, también chileno: brindó perfil, sustento y contenido al modelo que inspiraba a sectores mayoritarios de quienes gobernaron Chile entre 1970 y 1973. Fue, sin duda, un horizonte utópico que inspiró a las fuerzas de izquierda en los sesenta y ciertas medidas de la Unidad Popular. Estas fuerzas - fundamentalmente los partidos comunista y socialista, y también MAPU y MIR (aunque restringidos estos dos últimos a los modelos de Cuba y Vietnam) - proyectaban el socialismo real como alternativa de desarrollo que garantizaba justicia social, modernización y verdadera democracia, silenciando y/o justificando al mismo tiempo la represión sistemática que se ejercía allí contra la ciudadanía. En lugar de respaldar a los pueblos que vivían en el socialismo realmente existente, estos partidos simpatizaban acríticamente con los partidos comunistas en el poder. Es en este sentido que el Muro se enraíza en nuestra historia política reciente, y es chileno y a la vez espejo nuestro en tanto utopía y pesadilla. Explorar las razones del Muro incomoda a nuestra izquierda porque conduce inexorablemente a la responsabilidad moral que emana del hecho de respaldar dictaduras. Por eso, las fuerzas políticas que postulaban en los años sesenta y setenta a Alemania oriental como modelo de desarrollo se apresuraron en sepultar ese espejo y optan por bajarle el perfil al vigésimo aniversario de la caída del Muro.

Pero si se aspira a escribir una historia chilena coherente, inclusiva y con diversidad de voces, no puede olvidarse que la causa ideológica inicial para nuestra peor tragedia del siglo XX estribó precisamente en que un sector minoritario de la sociedad se propuso superar el atraso y la desigualdad basándose en un sistema que sobrevivía sólo gracias al Muro o, como en Cuba, a la insularidad, la emigración masiva de opositores y los errores cometidos por Estados Unidos ante 
Castro. El Muro de Berlín es un espejo que nuestra izquierda sepultó. En este sentido, a la izquierda que no criticó públicamente el Muro (como no critica hoy públicamente los 50 años del castrismo) le ocurre algo semejante que a esa derecha que jamás criticó al régimen de Augusto Pinochet. Con ello, a mi juicio, pierde la izquierda su supuesta superioridad moral frente a la derecha, a menos que se esgrima la lamentable lógica de que es condenable respaldar la represión de una dictadura contra la propia nación, mas “justificable” respaldar la que se ejerce contra otras naciones. Es en este nivel, que se da entre simpatizantes civiles de una y otra dictadura, donde se establece una simetría de responsabilidad política entre derecha e izquierda en la segunda parte del siglo XX, simetría que entorpece — por razones opuestas pero coincidentes - el examen de nuestra historia desde una perspectiva amplia y objetiva.

\section{La vida apacible}

No se vivía mal en la RDA. Por el contrario. Si uno renunciaba a la pretensión de viajar a Occidente, es decir, en muchos casos al simple deseo de alcanzar la acera opuesta de una amplia avenida dividida por el Muro, o bien disponía, como los dirigentes chilenos exiliados allí, visado para entrar y salir libremente del país, la vida resultaba barata, simple, ventajosa. El alquiler de los sencillos departamentos no podía superar el 10\% del ingreso familiar, la salud y la educación (comunista) eran gratuitas, los alimentos (sin la abundancia de Occidente) estaban subvencionados y no era caro no comprar libros (censurados), y no se pagaba impuestos. Desde luego, no se podía viajar a Occidente, y a los países socialistas sólo tras arduos trámites que podían ser rechazados, pese a que uno de los mayores anuncios lumínicos de Berlín este, de la desaparecida línea estatal Interflug, destacaba que la capital era una "ciudad abierta" y sus aeronaves llegaban a cuatro continentes. Tampoco se podía acceder a diarios o revistas, ni a la mayoría de los libros y películas occidentales, considerados "diversionismo ideológico" por el régimen, aunque uno podía enterarse de todo cuanto ocurría al otro lado del Muro por las radioemisoras y canales de televisión occidentales, lo que iba creando en el Este una existencia esquizofrénica.

Alemania oriental era una "sociedad de nichos" en donde uno se replegaba y hablaba en confianza o simplemente escuchaba o veía radio 
y televisión del “otro lado”. Los nichos los conformaban la familia o amigos escogidos. Lo que mejor lo representaba era la datscha (pequeña quinta de fin de semana, situada en las afueras de la ciudad, que poseían individuos de la clase alta socialista), donde éstos buscaban refugio y recibían a los amigos de confianza. Eran espacios reducidos en los cuales uno podía opinar con (cierta) seguridad sobre política, complicidad que sólo podía captarse si se hablaba bien alemán, o de lo contrario nunca la alcanzaba. Sospecho que fue esto último lo que les ocurrió a muchos dirigentes nuestros. Jamás se enteraron de lo que opinaban realmente los ciudadanos reales del socialismo real ni estaban en condiciones de leer entre líneas sus mensajes. ¿De dónde iban a obtener esa información confidencial? ¿De los apologéticos medios estatales, de los funcionarios alemanes, de la ciudadanía que los veía demasiado "izquierdistas" y dependientes de la solidaridad política y material del sistema? ¿O de los medios occidentales, calificados de imperialistas y revanchistas?

Creo que los chilenos que sí se daban cuenta de las aristas del mundo en que estaban eran los jóvenes que aprendieron el idioma como niños y compartieron con alemanes desde la escuela, donde no tardaban en constatar que la gran obsesión de sus compañeros educados desde la cuna en el socialismo real consistía en marcharse a Occidente. A los chilenos más maduros, el golpe se lo asestaba el régimen cuando querían casarse con germano-orientales. El trámite, largo, complejo, arduo, debía ser aprobado por la policía política y no otorgaba libertad de desplazamiento al cónyuge. Es decir, el chileno podía viajar a Occidente, pero su mujer e hijos alemanes quedaban detrás del Muro. Algo, desde luego, que sorprendía a cualquier chileno de entonces. En el fondo, era una violación a los derechos individuales que a algunos compatriotas les causaba agobio o los volvía cínicos, o bien los arrastraba a un mutismo paciente o a un "resentimiento" políticamente incorrecto, que lo convencía de que lo mejor era irse de algún modo a Occidente.

Amigos alemanes me dejaron entrever a menudo que soñaban con viajar por unos días a Occidente, aunque fuese dejando de rehén a la mujer o los hijos. Soñaban con ver simplemente el resto de la ciudad, la catedral de Colonia, el Rin, o la otra capital alemana, para no hablar de París, Roma o Londres, que estaban a escasas horas de vuelo. Otros confesaban que les gustaría mudarse al capitalismo para siempre, 
y la gran mayoría evitaba el tema de la misma forma en que lo evitaban en sus textos los escritores germano-orientales. ¿Cómo era posible escribir de la RDA o hacer películas u obras de teatro sobre ella sin mencionar la palabra ni la realidad del Muro? Pero así era. El partido gobernante no aceptaba que dicha problemática se abordara. El concepto era impronunciable. El emperador andaba desnudo y nadie podía decirlo. Simplemente esa era la vida que les había tocado, y los germano-orientales la vivían con estoicismo y resignación, tratando de imprimirle sentido a la existencia a través de una ideología que afirmaba que la tarea de los revolucionarios consistía en apoyar a las fuerzas progresistas del orbe (como a los chilenos del exilio y la resistencia a Pinochet), fortalecer el socialismo con el anónimo trabajo cotidiano y combatir la ideología imperialista. El futuro se reducía a un más de lo mismo.

A decir verdad, tanto en Cuba como en la RDA eso constituía una tensión insoluble para los dirigentes: los jóvenes, hartos de la vida gris y rutinaria del socialismo, lamentaban que no tuviesen la oportunidad de vivir al menos "tiempos decisivos" como los que habían vivido sus padres. En una crítica velada lamentaban no haber estado en "la primera hora”, en el inicio de la revolución socialista, en 1959, o los comienzos de la RDA, en 1949, cuando ambas repúblicas alemanas competían sin muro de por medio, y el socialismo aún parecía capaz de desplegar fuerzas productivas competitivas frente a Occidente. En más de una de sus novelas y entrevistas, la cubana Zoé Valdés habla con desagrado de los exiliados chilenos. Los critica porque llegaron con zampoñas, quena, charango y poncho al Caribe, cantando loas a la revolución, ocupando los departamentos que estaban destinados a esforzados cubanos que habían realizado por años trabajo voluntario para acceder a nuevas viviendas, y luego - los chilenos, se entiende- se habían ido, sin cesar de celebrar la revolución cubana, a vivir a Suecia, Holanda o México, a vivir el capitalismo y a integrar desde allá, alegremente, los comités de solidaridad con Cuba. Valdés, que vive en París, es una de las intelectuales cubanas más críticas al castrismo, y su rechazo a los chilenos es compartido por muchos cubanos que nos vieron a los chilenos como rompehuelgas ideológicos, lo que se ve refrendado en cierta medida por nuestra conducta "tránsfuga" en los socialismos reales. El número de exiliados chilenos que dejó el socialis- 
mo y se reinstaló en Occidente durante la dictadura de Pinochet refuerza esa apreciación crítica de la escritora a un desplazamiento del cual yo mismo formé parte. Aclaro: no critico la fuga del socialismo a Occidente, sino el ocultamiento de las razones de esa fuga.

Hoy, entre mis amigos alemanes, ni el más "duro" antiguo simpatizante de la RDA de la década del setenta cambiaría por un minuto la competitiva realidad de la economía social de mercado de la Alemania unificada por la existencia segura, regulada y monótona del "primer estado de obreros y campesinos en territorio alemán”. Es cierto que los alemanes orientales incluyen en su concepción política un poderoso ingrediente de justicia social e igualitarismo, heredado de su experiencia socialista, que lleva a muchos a votar por los antiguos comunistas (ya tan renovados que no postulan partido único, ni Muro, ni separación de Europa, ni estatización total), pero nadie quisiera volver al pasado, a un pasado que los alemanes han instalado en un minúsculo museo, situado frente al Alexanderplatz: el Museo de la RDA.

\section{Yo también creí en eso}

Pero la caridad comienza por casa. Yo también creí en todo eso. Creí en mi juventud temprana a pie juntillas en el socialismo real como alternativa de desarrollo y prosperidad para Chile. Creí en que ese sistema, que conocí primero a través de las publicaciones del partido y la juventud comunista así como de revistas oficiales de las repúblicas populares — revistas de portada a color y de páginas gruesas, brillosas, en las que siempre aparecían obreros y campesinos sonrientes, bien vestidos y alimentados, felices de habitar la utopía-, presentaba la mejor alternativa para mi país y América Latina, una vía de modernización y justicia social, un mundo infinitamente superior al que teníamos entonces, una opción a la que se oponían "los intereses espurios del imperialismo norteamericano y las burguesías nacionales”.

Por eso pedí mi ingreso a la juventud comunista en 1969 y por eso, después del golpe militar de 1973, preferí irme al Berlín oriental que al occidental, cambiar de bloque en medio de la Guerra Fría, irme a vivir detrás del Muro, en la utopía nuestra, como buen comunista. En mi calidad de egresado del colegio alemán, y tras haber aprobado exámenes que me permitían ingresar a universidades alemanas occidentales, era 
cuestión de trámite matricularse en ellas. Pero cuando uno es joven e idealista (ambas cosas a menudo van de la mano), uno muestra una coherencia (consecuencia, diríamos en Chile) que difícilmente se repite en la vida. Lo lamentable fue que rápidamente comencé a notar conductas desalentadoras en el socialismo: dirigentes y funcionarios del gobierno chileno depuesto que habían podido escoger entre exiliarse en París, Roma, Amsterdam o Washington, por un lado, y Moscú, Bucarest, La Habana o Sofía, por otro, optaban por Occidente, desde luego. Otros, los que no habían podido escoger y les tocaba en suerte digamos Varsovia, hacían discretas diligencias para lograr que el partido "los enviara a cumplir misiones” en metrópolis occidentales. Me llamaba la atención que muchos de los dirigentes "del pueblo", aunque no vivían como "pueblo" en Chile, ahora, en el exilio, seguían celebrando el socialismo aunque desde el capitalismo. Figuras emblemáticas de la izquierda, algunas de las cuales habían exigido a Salvador Allende radicalizar la marcha al socialismo, preferían Europa occidental y Estados Unidos, o bien Ciudad de México o Caracas, en lugar del mundo socialista, eso sí, como si parafraseasen un poema de Heberto Padilla: dar un paso adelante y dos atrás, pero "aplaudiendo" siempre al socialismo.

Nunca he logrado establecer la causa última que me empujó a ser comunista. Tal vez fue el "Zeitgeist”, no mi cómoda procedencia pequeñoburguesa. Y sospecho que los dirigentes comunistas de extracción obrera tenían razón al desconfiar de alguien que venía de un colegio particular y padre masón. En el fondo, para mí los derechos individuales eran cosa sagrada, convicción que en algún momento colisionaría con la preeminencia de la masa y la doctrina comunista. Sospecho que me sentí atraído por esa ideología en el instante en que descubrí en los cerros de Valparaíso la miseria, en que me di cuenta que mientras yo iba a un colegio privado, otros iban a escuelas sin recursos, que mientras yo tenía casa y vacaciones, otros habitaban casuchas y mediaguas (Valparaíso no oculta diferencias sociales, por el contrario, las exhibe como ninguna otra ciudad), que mientras yo aprendía otras lenguas y podría estudiar en el extranjero, otros apenas aprendían a escribir y trabajaban desde niños. Creí realmente que el socialismo solucionaría aquello, que la oposición a Allende trataba de impedir que el pueblo se liberara, y que lo que se decía de los países comunistas no era cierto, porque las masas en la Plaza de la Revolución y la existencia de las repúblicas populares probaban la superioridad del socialismo. 


\section{4. ¿Lo sabían nuestros dirigentes?}

En el colegio alemán en que estudié, desde temprano los profesores alemanes nos hablaron de la existencia del Muro, de la separación de familias, de la imposibilidad de salir de la RDA, algo que, en mi conciencia juvenil contestataria, más que un drama, me parecía una patraña. Después, cuando llegué a vivir detrás del Muro, comprobé que lo que me habían contado en el colegio no era cierto, pues la realidad era peor de lo que me la habían pintado. Es decir, llegué al socialismo con el escepticismo inoculado en las venas. Por eso siempre me he preguntado si los dirigentes chilenos exiliados en la RDA conocían a ciencia cierta el carácter dictatorial del régimen socialista en que vivían y al cual apoyaban.

¿Lo conocían, o realmente fueron incapaces de ver lo que palpitaba bajo la exitosa superficie que pregonaban los medios oficiales, los únicos permitidos? ¿Sabían que vivían en un sistema dictatorial que era la antítesis de lo que exigían para Chile, como libertad de expresión y reunión, derechos humanos, fin de la policía política, término del exilio y del destierro como castigo contra los opositores? ¿ $\mathrm{O}$ pensaban que esa contradicción no acarrearía costo alguno en un país que estaba lejos y registra una mala memoria proverbial? Es un tema que aún está pendiente entre nosotros, y que es crucial pues se relaciona con la ética. ¿Lo sabían o no lo sabían? No quiero mencionar nombres para no personalizar la discusión. ¿Lo sabían y callaban por cálculo mezquino, conveniencia personal y de grupo, porque a esas alturas ya no podían lanzar por la borda sus convicciones y militancias sin tener que pagar un alto precio? ¿O lo ignoraban y creyeron realmente que los parlamentos socialistas representaban a la ciudadanía, y por ello probablemente se sorprendieron cuando Europa oriental se rebeló en 1989 contra el comunismo? Si lo sabían y pensaban que sus dos únicas alternativas consistían en vivir bajo la dictadura de Augusto Pinochet o la de Fidel Castro, y que ante eso correspondía identificarse con la del segundo, la posición es de una inmoralidad inaceptable. Y si, pese a haber vivido en países comunistas, no fueron capaces, como dirigentes, de darse cuenta que habitaban en un régimen represivo que les mostraba su mejor cara, treta que desde luego no convencía a su población, entonces esos dirigentes carecían de autoridad para continuar en política. No está capacitado como político respe- 
table en democracia quien, viviendo en una dictadura totalitaria, no fue capaz de darse cuenta en qué tipo de sociedad vivía.

El silencio, o bien las declaraciones abigarradas de esos dirigentes - tanto de aquellos que lo supieron todo desde el primer momento como la de aquellos que sostienen haber creído de buena fe que habitaban el mejor de los mundos posibles-, fue un instrumento para asegurar la supervivencia política personal y la del partido al que se pertenecía, con vistas a un futuro Chile democrático. Aun espero el mea culpa profundo y honesto de esos dirigentes — muchos de los cuales ya se retiraron, bien pasando a la jubilación o a los negocios privados. Algo semejante ocurre, lo señalé más arriba, con sectores de derecha relacionados con el régimen de Pinochet.

\section{Caen las vendas}

Recuerdo una conversación con una estudiante alemana de la Universidad Karl Marx, de Leipzig, en 1974. Reinaba cierta confianza entre nosotros, gracias a mi dominio del alemán. Mientras afuera, en la Strasse des 18. Oktober, caía la nieve, me preguntó:

- ¿Y tú, por qué escogiste vivir en la RDA?

- Porque no quería vivir en una dictadura.

La muchacha me miró incrédula:

—¿¿Y la dictadura chilena te dejó salir del país?

- Pues, si no te están buscando, claro que sí. Te deja.

-Aquí no es así. ¿Y escogiste la RDA?

—Claro, soy comunista. La RDA es un modelo para mi patria.

La muchacha, miembro de la organización juvenil oficial, FDJ, comentó azorada:

- ¿Y escogiste venir al socialismo real? Curioso. Yo lo único que deseo es irme de aquí y vivir en Occidente, y no lo puedo hacer hasta que jubile.

Eran diálogos dolorosos porque tu utopía se estrellaba contra la realidad, la hacían añicos los supuestos beneficiados del sistema. Era, desde luego, un sistema que rechazaban los alemanes orientales desde el comienzo del dominio soviético, como sostiene Ralf Dahrendorf en 
sus Reflections on the Revolution in Europe. Los comunistas alemanes, instalados en el poder por las tropas soviéticas en 1949, apostaron por la letal "vanguardia leninista”, una concepción que parte del supuesto de que los elementos políticamente más esclarecidos del partido saben lo que le conviene al pueblo y que al final éste terminará por aprobar las opciones de la vanguardia. Craso error. Es por ello que nunca se realizan elecciones libres en un sistema comunista. Nadie en su sano juicio considera que es preferible que otros escojan lo que más le conviene a uno mismo.

A la larga para mí, como para otros, el mayor antídoto contra el comunismo fue haber conocido el socialismo real. En realidad, no deja de llamar la atención que sus adversarios más críticos provengan de quienes vivieron en el socialismo, y que sus defensores más fieles se hallen entre quienes nunca vivieron en él. Basta consultar bibliografías o medios de prensa para confirmar esta impresión. Haber conocido a fondo la realidad de partido único de Cuba (que hoy lleva medio siglo, entonces sólo cumplía quince años) me convirtió en un crítico fundamentado de ese sistema, de lo contrario probablemente aún andaría en ciudades norteamericanas o europeas asistiendo a "mítines de solidaridad con la revolución cubana” y creería que el 99,7\% de los cubanos siempre ha votado por Fidel Castro. Haber vivido en la RDA y haber conversado en confianza con su gente me libró del bochorno de haber justificado el Muro y de haber pensado que éste en realidad era, como lo afirmaba el gobierno, “una valla antifascista”, levantada voluntariamente por los obreros y campesinos para evitar ataques de Occidente. Sospecho que la mayoría de los chilenos que vivimos en el socialismo real tenemos en nuestro fuero interno una opinión crítica sobre él, y que lo que me diferencia de un militante comunista en esta materia es simplemente el discurso sobre el Muro. No nos diferencia la percepción de la realidad, sino el discurso que articulamos sobre ella, uno crítico, el otro justificador o sin palabras, silencio que siempre es cómplice ante dictaduras.

\section{Los intelectuales}

No hay duda de que a lo largo de veinte años, los entonces dirigentes de nuestra izquierda han sabido eludir la corresponsabilidad que les cabe por haber vivido en un régimen totalitario sin haberlo 
criticado, y por haber dirigido a comunidades de exiliados chilenos mediante los instrumentos de un estado dictatorial. No se trata de proponer una cacería de brujas, sino de colocar el pasado en su justo contexto. Muchos dirigentes amantes de la crítica de las armas nunca se sometieron al arma de la autocrítica. Han preferido ampararse en el silencio. Pero existe otra opción, desdeñada en Chile, para parte del exilio acrítico de esos años.

Me refiero a la opción que representa Stefan Heym, gran intelectual disidente germano-oriental, un escritor notable, que vivió al filo de la navaja, siempre a punto de ser expulsado de la RDA, publicando libros críticos en Occidente, manteniendo un cuidadoso equilibrio con el poder comunista, algo que le permitió sobrevivir a la RDA en la RDA. Heym subrayó antes de morir, como justificación por su identificación general con la alternativa al capitalismo que representaba la RDA, que no podían exigirle "echar por la borda" gran parte de las causas que habían definido su vida y su existencia. Algo similar ocurre con Stephan Hermlin, destacado poeta germano-oriental, que se desplazaba entre el reconocimiento y la desconfianza oficial, intocables ambos, Heym y Hermlin, quizás por haber liberado a Alemania de Hitler integrando los ejércitos de Estados Unidos y Gran Bretaña. Al momento de fundarse, el 7 de octubre de 1949, la RDA impulsó una política que intentó atraer a los principales escritores alemanes desperdigados por el mundo, lo que le permitió reclutar a Bertolt Brecht y flirtear con Thomas Mann, a quien se le concedió amplio espacio editorial. Con el florecimiento de la Guerra Fría y la construcción del Muro, la RDA eliminó los escasos espacios de libertad que ofreció inicialmente a intelectuales independientes.

Tanto Heym como Hermlin, que dialogaban con el poder totalitario, expresaron al final de sus días, después de haber presenciado el absoluto rechazo del pueblo hacia la RDA, que habían sido críticos y no se podía exigir de ellos que renegaran de todo lo que habían creído en el pasado. En esa petición de benevolencia dirigida a la opinión pública expresaban a la vez la responsabilidad política del intelectual y los riesgos que corre al identificarse con el poder político no democrático. Existe también una alternativa autocrítica más de izquierda y comprometida con el sistema, aquella que representa Markus Wolf, el legendario espía. Años antes de la caída del Muro, el general renunció al espionaje, se dedicó a escribir libros y a promover una concepción 
democrática de la RDA, algo que expresó en público ya cuando era demasiado tarde, en noviembre de 1989, cuando las masas inundaban las calles y los dados estaban echados contra el socialismo.

Ralf Dahrendorf plantea un argumento que pudiera resultar interesante para nuestra izquierda, como muchas de sus reflexiones sobre el fin de los socialismos reales. Sostiene que el socialismo real fue en el fondo un modelo que intenta acelerar el tránsito de sociedades precapitalistas al capitalismo, de allí su déficit democrático. Desde esa perspectiva también es posible hilvanar una suerte de tibia defensa de la izquierda chilena en relación con el apoyo que prestó a las dictaduras de Europa del este. En todo caso es notable que nuestra izquierda no haya aprendido de sus ex aliados desplazados del poder, que en los últimos veinte años basan su renovación asumiendo sus errores y abusos, separándose de figuras y símbolos de antaño, pasando por una reformulación de políticas y utopías, y sometiéndose a la revisión crítica y pública de la propia historia. Es precisamente el hecho de barrer el polvo — el polvo del Muro, casi me atrevo a decir- bajo la alfombra lo que le impide a ese sector regresar al escenario con credibilidad y coherencia, y con plena autoridad para enrostrarle a la derecha su respaldo a Pinochet. Mientras esa crítica no vaya acompañada de la autocrítica, la primera me sigue pareciendo táctica y efectista, hipócrita. Desgraciadamente, la izquierda sigue cultivando el olvido, a pesar de que en otro sentido lo combate. Sigue negándose a exhibir su pasado, a recordar sus antiguos referentes ideológicos y aliados, pese a que éstos los financiaron durante decenios, y hoy o han dejado de existir o se han renovado.

\section{7. ¿Qué opinas?}

Corre 1981. Noche en Berlín este. Estoy a punto de irme definitivamente a Alemania occidental. Me visita un ex ministro del presidente Salvador Allende para conversar sobre Chile y la RDA. Su alemán es deficiente. Tiene más de cincuenta años, lleva unos cinco años en la RDA e intuye que jamás dominará el idioma como para explorar las profundidades del alma germano-oriental. En un momento de la conversación, en la calle, cuando estamos despidiéndonos, sin que yo le haya revelado que planeo marcharme a Bonn con la ayuda de amigos, 
me pregunta desde la autoridad que le confiere su paso por el gabinete de un hombre devenido mito:

—Dime una cosa, ¿qué porcentaje de los alemanes, crees tú, apoya el socialismo?

Es la pregunta honesta, pero políticamente incorrecta, de un hombre que — curiosamente - no tardará en pasar a militar en el partido comunista chileno. En rigor, esa pregunta está fuera de lugar. Todas las elecciones de la RDA demuestran algo de forma enfática: el 98,7\% de los electores aprueban los candidatos del gobierno al parlamento, y Erich Honecker, casi alcanza al 100\% de apoyo. Eso, según los votos y los medios comunistas. ¿De dónde puede surgir esa pregunta? ¿De su desconfianza hacia los medios oficiales, o de un interés por saber realmente cuál es mi postura definitiva frente al socialismo?

— ¿La verdad a la milanesa? —le pregunto.

- Sí — dice el ex ministro mientras fuma y sus grandes ojos café brillan con esperanza y curiosidad en la noche de Berlín. — Tal vez un $30 \%$ de la gente está con el sistema —le digo. -Noooo, imposible —alega—. Yo creo que los medios occidentales deben influir en un 20 o 30 por ciento, pero el resto está con el socialismo. Es que viven bien acá.

Entonces digo algo definitivo y provocador, no por provocar, sino porque me parece que es lo más cercano al modo en que, supongo, debe pensar un chileno corriente:

- Si no hubiese muro, la gente escaparía en tropel. Y basta con que se escape la mitad de los médicos o de los conductores de camiones para que esto colapse.

Lo dije, y ahora lo traigo a colación no porque quiera presentarme como pitonisa, sino porque era parte del acervo de percepciones de los alemanes orientales. Todos, cada uno desde que tenía uso de razón, lo sabía, lo intuía, porque iba a ser, tal vez, parte de esa ola migratoria si el Muro caía y quedaban sólo dos opciones: vivir en el capitalismo o en el socialismo. Es por eso que la RDA claudica tan rápido en 1989. Saben sus dirigentes que sin Muro el modelo es inviable, que entre socialismo y capitalismo, la gente prefiere el capitalismo con todas sus inseguridades, diferencias y libertades. Pero ahora el ex ministro me mira, decepcionado. 
— ¿Tú crees que no volverían? — pregunta con la voz trémula mientras aspira el humo y mira hacia el cielo estrellado.

-No es necesario que escapen todos para que todo esto se venga abajo - digo y pienso que es imposible que el político no se haya dado cuenta del país en que vive, de lo que piensan sus habitantes, que la ideología (y la falta del idioma alemán) le impiden ver la realidad, palpar lo que bulle debajo de la delgada y brillante capa que los medios y la propaganda oficial tienden sobre la triste realidad socialista.

\section{La autocrítica post Muro}

Durante una mesa redonda sobre la caída del Muro, celebrada recientemente en el Instituto Iberoamericano de Berlín, un dramaturgo chileno, que vivió exiliado en Berlín oriental, manifestó con mucha honradez, o al menos así me pareció, que él y numerosos compatriotas que residían en el país socialista tardaron en darse cuenta del mundo represivo en el que vivían. Sostuvo el artista que sólo a posteriori, mientras experimentaban la libertad individual post Muro, alcanzaron plena conciencia de lo que significaba disponer de opciones individuales con respeto a la vida, sin la mediación del Estado al que estaban acostumbrados. En ese sentido tuvo la deferencia de reconocer que él, al escuchar a comienzos de los años 80 que yo me marchaba a Alemania occidental, había pensado, estimulado por la lógica de las acusaciones ideológicas, que yo podía ser un agente occidental. Lamentaba ahora no haber interpretado ese desplazamiento como expresión de una insatisfacción con la falta de libertades en la RDA de parte de un chileno que exigía esas libertades para Chile.

Durante esos días, almorzando en casa de un prestigioso académico alemán, emérito de la Universidad de Humboldt, alguien que se identificó desde la juventud con la RDA y representaba la academia de ese país, reconoció hidalgamente que no podría volver a vivir entre los muros de la RDA, porque había comprobado que los espacios actuales de libertad eran incomparables con los estrechos marcos que el socialismo real ofrecía. En ambos casos - tanto en el del chileno como del alemán- se trata, sin embargo, de intelectuales críticos al sistema capitalista, de defensores de ciertos logros del socialismo real en materia de equidad salarial, acceso a la educación y la salud, pero renuentes 
a cambiar el capitalismo actual por un retorno a la vida regulada, gris y triste del socialismo real.

Lo que me llama la atención es que en Chile no existe literatura suficiente sobre esta etapa que es parte de la historia nacional. El historiador marxista Eric Hobsbawn detalla en sus memorias que durante un encuentro en los noventa, en la televisión holandesa, con el ex maestro de espías germano-oriental, Markus Wolf, éste admitió que, a partir de la información que manejaba en los setenta sobre el atraso tecnológico del socialismo, los cuellos de botella económicos y el descontento popular, no veía posibilidad alguna de que su sistema triunfara. Los líderes comunistas habían caído en su propia trampa. Nadie se atrevía a ponerle el casco al gato. A partir de entonces, algo que los ciudadanos de la RDA y uno mismo advertía, la tarea consistía en administrar la crisis que conducía indefectiblemente a la derrota en la emulación con Occidente. Llama la atención también que durante años, y más aun en este año en que se cumplen 20 de la caída del Muro, en Alemania y ex países socialistas se debate activamente la responsabilidad que partidos e individuos tuvieron en el apuntalamiento y desmantelamiento de esas dictaduras, debate que, por cierto, no ocurrirá en Chile.

Pese a que nuestra izquierda apostó por decenios por esos modelos (a comienzos de los setenta el PC y el PS comprendían cerca del $35 \%$ del electorado) y recibió solidaria acogida en el exilio después del golpe de Estado, la izquierda evade esa discusión. Resulta curioso, primero, porque fue ella el alumno regional más avanzado de esa vía de modernización, y segundo porque estrechó vínculos y recibió respaldo financiero durante el exilio de esos modelos. Al examinar a fondo el caso chileno, comprobamos que nuestro modelo de transición pacífica al socialismo era el más cómodo para la Unión Soviética y sus aliados en una época de colaboración entre ambas superpotencias.

En nuestro país no aparece, sin embargo, la aceptación de responsabilidades políticas de la izquierda por haber roto, en 1970, con la tradición democrática de Chile y haber declarado que el estado burgués debía ser sustituido por uno socialista. En lugar de ese debate sobre las dictaduras de "los partidos aliados", se pone el énfasis en la condena a la represión de la dictadura de Pinochet y se despliega — con razón— el drama de las víctimas del régimen militar. En lugar de asumir responsabilidades por el quiebre legal que alimentó, la izquierda optó por enfo- 
carse en las denuncias internacionales contra la dictadura y en destacar a las víctimas de "nuestra" dictadura. Escasean hoy en Chile mesas redondas, libros de ensayos o novelas que aborden ese tema desde una perspectiva amplia e inclusiva, que apunte a la reflexión y a la construcción de nuevas plataformas de acuerdo nacional.

\section{El Estado de escritores}

Cuando la RDA fue fundada, una de las ambiciones culturales centrales fue atraer a prestigiosos escritores alemanes que habían buscado el exilio durante el régimen nazi. La zona de ocupación soviética se esforzó desde el comienzo por transformarse en el "Schriftstellerstaat" (Estado de escritores) y el futuro Estado en un Estado de escritores, claro está, de aquellos que suscribían su ideología o no la criticaban de modo frontal. Figura clave de la estrategia fue Johannes R. Becher, quien regresó desde Moscú al Berlín liberado con la tarea de reclutar escritores, tanto de aquellos que habían sufrido represión y exilio, como de quienes se habían dejado instrumentalizar por el régimen nazi. Entre muchos otros destacaron Hans Fallada, Arnold Zweig, Anna Seghers, Bertolt Brecht y Gottfried Benn. Es la agudización de la Guerra Fría, la prosperidad de Occidente, el Muro y el estalinismo lo que liquida esa apertura inicial y restringe la expresión artística hasta la desaparición de la RDA.

Mientras vivíamos en la RDA, comprobábamos cómo el socialismo era incapaz de permitir el libre flujo de ideas entre Este y Oeste. De los escritores se esperaba lealtad política al sistema, lealtad que debía manifestarse también en forma estética, se transmitía hacia los escritores a través de la Asociación de Escritores de la RDA. Las orientaciones estético-literarias, aprobadas por los propios escritores, exigían una literatura que reflejara "partidariamente" las condiciones de la construcción del socialismo y contribuyera a que los trabajadores participaran de forma entusiasta en esa construcción, y exigían realismo socialista. Por esto en pocos países del mundo la literatura tenía tanta incidencia en la política como en la RDA. Los funcionarios partían de la convicción de que la literatura moldea conductas y ciudadanos, crea estados de ánimo, y puede criticar la sociedad socialista y sus deficiencias, y se halla en manos de intelectuales, en su mayoría miembros de una peque- 
ña burguesía políticamente inestable, que se siente atraída por el capitalismo. Por esto, a los escritores se les conminaba a conocer la vida de los trabajadores y llevarles la voz del partido en el perfeccionamiento del socialismo.

No había en Alemania oriental espacio para obras críticas, pero sí lo había en Alemania occidental, y la televisión y las radioemisoras de allí comentaban precisamente los libros críticos. El mensaje llegaba entonces a través del país vecino. Stefan Heym siempre se movió entre ambas Alemanias en materia de publicaciones. Publicando en Occidente lo que le prohibían en el Este, aunque fue leal hasta el final con el "Estado de obreros y campesinos". Christa Wolf, por el contrario, era el mayor escritor de exportación de la RDA. Bertolt Brecht, el principal intelectual de la RDA, que pasó la parte final de su exilio en California y regresó a Berlín cuando la RDA le ofreció el Berliner Ensemble, Brecht, icono de la cultura comunista, tomó sin embargo la ciudadanía austríaca y mantenía cuenta bancaria en Suiza. Amaba el socialismo real, pero, como muchos dirigentes nuestros, era un pragmático.

\section{Nuestro CHAF de cada día}

Cuando recuerdo mis años detrás del Muro, que logré atravesar un par de veces esgrimiendo siempre buenas razones ante el Comité Chile Anti Fascista (CHAF) que se encargaba de tramitar la visa de salida y regreso de la RDA, me queda claro que el fenómeno más importante de la vida berlinesa era precisamente el Muro. Curiosamente, ni el cine, ni la literatura hacían referencia a él. En el lenguaje estético el concepto estaba prohibido. No hay novela de la RDA que hable del Muro en forma inequívoca. Incluso el concepto mismo estaba vedado. El partido en el poder lo calificaba de concepto imperialista y deformador de la historia y la realidad. Por esa prohibición uno podría afirmar que la literatura germano-oriental post 1961 queda descalificada en su intento de dar cuenta de la condición humana de entonces. Existe sólo un relato largo, publicado, que aborda claramente el tema de la fuga a Berlín occidental. Es Der geteilte Himmel (El cielo dividido), de Christa Wolf, publicado en 1963, que habla de una pareja de novios dividida por sus ambiciones: mientras Manfred opta por irse a vivir a Berlín occidental, Rita va a buscarlo para que regrese a la ciudad de Halle, en el este alemán. En esos días se levanta el Muro (13 de agosto 
de 1961) y los amantes quedan separados. Rita intenta quitarse la vida, pero despierta en un hospital y comienza a recordar lo ocurrido. El relato fue llevado a la pantalla grande por el reconocido director Konrad Wolf, hermano del espía Markus Wolf, en 1964. Después el tema del Muro se convirtió en tabú en la literatura y el lenguaje oficial de la RDA.

Emplear en la RDA el término "die Mauer" (el muro) constituía un delicado faux pas que revelaba problemas ideológicos en el exponente y acarreaba problemas políticos. De ese modo, el concepto desapareció del uso público, aunque seguía existiendo en el resto del mundo y en el lenguaje privado de los ciudadanos. La dirección del partido, consciente de que gran parte de lo que vemos lo percibimos a través del lenguaje, suponía que eliminar el concepto, eliminaba el Muro como realidad. Carlos Cerda, ya instalado de vuelta en Chile, recoge en su novela Morir en Berlín la experiencia del CHAF en el control de los exiliados que ejercían funcionarios del gobierno germano-oriental y dirigentes chilenos. Era en esos instantes - cuando uno advertía que el desplazamiento a Occidente dependía de permisos que otorgaban funcionarios-, uno se preguntaba qué papel hubiesen jugado esos compatriotas en un sistema socialista chileno.

\section{Escena en el S-Bahn}

Una noche de invierno, cuando viajaba tarde en un coche destartalado del tren urbano (Stadt-Bahn) de Berlín oriental, un viejo usó el concepto que el gobierno no quería ver mencionado. Fue un viejo borracho. Llevaba un abrigo sucio y un maletín con botellas de cerveza. En cuanto vio subir a un uniformado del regimiento a cargo del resguardo de la frontera, se puso de pie, se acercó a él y le gritó ante el estupor del resto de los pasajeros:

—Mörder! Mörder! Mörder! (¡asesino!, ¡asesino!, ¡asesino!).

Consternados, los pasajeros no podíamos creer lo que estaba ocurriendo. Sabíamos qué pasaría a continuación: el soldado de elite llamaría a refuerzos y el pobre viejo terminaría sus días en una cárcel política. Pero el soldado, demasiado joven y extenuado, y a la vez sorprendido, y viendo que nadie decía nada, que todos sólo observaban 
la escena como si fuese un sueño, optó por permanecer hierático, auscultando la noche a través de la ventana, que le devolvía su imagen y la del borracho insultándolo.

— ¡Abajo el Muro! Mörder! —repetía el viejo lleno de ira y dolor.

Al guardia de frontera, efectivo de la unidad más leal al sistema, no le quedó más que bajarse en una estación y dejar el carro en poder de su adversario, que siguió bebiendo sin que nadie le expresase una palabra de aliento o desaprobación por su conducta.

\section{País de nichos}

Dicen que, en cierto sentido y en cierta etapa de la vida humana, la RDA era un país ideal para vivir en él. No había duda de que la infancia constituía una gran etapa, al menos así lo registra la experiencia y encuestas post 1989. No había otro país en el mundo donde la mujer tuviese mayor participación en la vida laboral y donde el 100\% de los niños contase con salón cuna y jardín infantil para que sus madres pudiesen asistir al trabajo. Todos los niños encontraban un lugar semejante y encontraban colectivos y maestros, espacios adecuados, no de lujo, pero suficientes, y un ambiente en el cual iban creciendo protegidos por una ideología que convertía a los iconos y líderes políticos - Marx, Lenin, Grotewohl, Ho Chi Minh, Thälmann, Honecker, Allende - en símbolos paternales junto a los cuales se crecía. Se crecía en un mundo de sueños, protegido, convencidos de que la RDA era el mejor país del mundo, que formaba una alianza con los demás países socialistas y luchaba por los pobres del mundo. Al frente, en la vereda contraria (nunca se afirmaba: al otro lado "del Muro"), estaban el imperialismo, los capitalistas, políticos que dominaban sobre los trabajadores y campesinos, desataban guerras y respaldaban regímenes dictatoriales. Era el mejor de los mundos posibles...

Hasta que a cierta edad, siempre traumática para los ciudadanos de la RDA, descubrían, por lo general en la intimidad del hogar y de labios de sus padres, que vivían en una prisión rodeada de muros y alambradas, de la cual no se podría salir hasta que jubilara y sobre la cual no se debía comentar en público. Era el momento más duro de los 
jóvenes germano-orientales, el de la toma de conciencia de que no eran sujetos libres y protegidos por un Estado bienhechor, ni aliados de las mejores causas de la humanidad, sino prisioneros de por vida en un sistema que no aceptaba la disidencia, que premiaba con plazas de estudio y los mejores trabajos sólo a quienes se mostraban obsecuentes con el poder. Era el despertar político real. Se vivía bajo una dictadura sobre la cual no se podía hablar, rodeado de muros y alambradas que no existían ni en el lenguaje personal ni en el arte ni la literatura, un aislamiento que se hacía más doloroso al escuchar las radioemisoras o ver los canales de televisión de Berlín occidental, que llevaban a diario, minuto a minuto, mensajes e imágenes de un mundo inalcanzable que se alzaba a menos de un kilómetro de distancia, muchas veces a la vista desde una estación de trenes o el balcón de un edificio.

A mí esa sensación me sobrecogía. Por eso me instalé el verano pasado en la Oderbergerstrasse, en el barrio del Prenzlauer Berg, inmediatamente junto a lo que fue otrora la tierra de nadie, la franja de la muerte, el Muro. No me cansé de cruzar una y otra vez la Bernauer Strasse, donde antes se elevaba el Muro y sus alambradas, esa breve distancia que millones soñaban cruzar, que centenares murieron en el intento de hacerlo, que millares pagaron con cárcel por planear hacerlo o saber de quienes pretendían hacerlo y no lo denunciaron a las autoridades. No me cansé de cruzar esa Bernauer Strasse, de sentir de nuevo dolor por todos mis amigos y amigas, grandes amigos y noviecitas, que siendo alemanes y alemanas, no podían cruzar y que en su imposibilidad subrayaban que eran seres de segunda clase, mientras un extranjero venido del extremo del mundo sí podía hacerlo, y podían hacerlo las palomas y los gorriones de Berlín.

El exilio chileno sirvió a eso. Y en cierta forma también llevamos una responsabilidad que nunca hemos querido afrontar. Es más fácil seguir insistiendo en que aquellos chilenos que se marcharon de la Alemania oriental y la criticaron eran "mal agradecidos” y "agentes de la CIA o del BND”, que admitir que se había callado ante el encierro de 18 millones de seres humanos, entre los que se vivía y de los cuales se conocía a la larga los sueños y frustraciones de desplazamiento, de cruzar a Berlín occidental aunque fuese por una vez en la vida y por unas horas. No hay relatos ni libros del exilio chileno que expresen ese dolor y esa vergüenza, solidaridad con los alemanes germano-orientales, que a lo sumo podían acompañarlo a uno hasta la Friedrichstrasse, a despedirlo a 
uno antes de que uno, minutos más tarde, llegase a Berlín occidental y viajase de allí a París o Bruselas, al mundo, como un ser libre.

Zoé Valdés se queja de los chilenos en este sentido. Nos mira con desprecio desde su literatura. Llegábamos a Cuba a apropiarnos de sus departamentos y plazas de estudio por el simple hecho de ser revolucionarios derrotados por Pinochet, celebrábamos al régimen (que entonces "sólo" tenía 17 años, no los cincuenta de la actualidad), contábamos historias terribles de la represión de Pinochet pero sin escuchar ni por un minuto la de la policía castrista contra quienes pensaban diferente, y luego, sin dejar de cantarle a la revolución, nos íbamos de La Habana a vivir a Estocolmo, Roma, Ciudad de México, Caracas o París. Es una historia de la cual no hablamos, que hemos castigado con el silencio, que evitamos hundiéndola en la desmemoria, sepultándola en el olvido, en un esfuerzo por pulir nuestra imagen de víctimas de la historia, de ocultar nuestros protagonismos como hechores y cómplices de la violencia en la historia.

\section{Conversando frente al Wandlitz}

Julio del 2009. Una casa cerca del lago Wandlitz. Es la casa de Tanja, la hija de Markus Wolf, el espía mítico. El telón de la posguerra ya cayó. Tanja está casada con un ex alto oficial del espionaje de Alemania del Este, encargado de infiltrar Alemania occidental (tarea que cumplió con éxito y la ayuda de su suegro ya fallecido). Ambos me reciben a cenar con mi esposa y una pareja amiga en el jardín de su casa, bajo la sombra de árboles frondosos. Saboreamos platos de origen ruso (su padre creció en la Unión Soviética, hasta donde su abuelo huyó escapando de Adolfo Hitler), bebemos vodka y unos mojitos, pero sobre todo hablamos, hablamos sobre lo que ha sido haber creído en un proyecto popular que se desplomó en un cerrar de ojos porque el pueblo lo derrumbó. Son grandes perdedores de la historia reciente.

Escucho del matrimonio, hasta hace 20 años integraba la crema y la nata de la nomenklatura germano-oriental, algo que ya he oído mucho de funcionarios alemanes orientales de la RDA: que no es fácil echar por la borda las convicciones políticas de toda la vida. Son palabras que al menos quisiera escuchar de compatriotas míos, que ayer apoyaron el modelo y hoy miran hacia otro lado. Para el oficial de inteligencia, el primer día de la reunificación alemana comenzó con un 
grupo de agentes occidentales tocando a su puerta con orden de allanamiento. Él ya había escapado a Moscú. Sólo volvió a Alemania tras ser amnistiado. Él y su mujer recuerdan a los exiliados chilenos que llegaron en masa a partir del once de septiembre de 1973, sienten que sus propias vidas quedaron marcadas por la suerte que corrían los luchadores por el socialismo en una alejada tierra latinoamericana y admiten que les costó celebrar la recuperación de la democracia de sus aliados porque en esos años moría su propio estado, la RDA.

— ¿Y cómo les va a esos líderes chilenos que se exiliaron aquí? - me pregunta el ex oficial.

—En el poder. Supongo que les va mejor que a ustedes —repongo.

-Aquí no podía irnos de otra forma — comenta Tanja con mirada triste- Con mi padre sabíamos que Mielke (el jefe de la Stasi) tenía micrófonos en nuestra casa; y Honecker, cuando regresaba por las tardes a Wandlitz (ciudadela donde residía la dirigencia germano-oriental), cruzaba apurado y cabizbajo el jardín para refugiarse hasta el otro día en su vivienda... 